\title{
Aiding in the evolution of translational medicine: "Bridging Academia and Industry" in the field of neuroscience
}

\section{Raghu Kiran Appasani*}

Appasani Research Conferences \& Educational Institute, Gene Expression Systems, Inc., Waltham, MA, USA

${ }^{*}$ Correspondence: raghu@expressgenes.com

Neuroscience has progressed dramatically since the time of Ramon y Cajal in 1894, and the advancement of technologies, such as microscopy, molecular biology, electrophysiology, as well as breakthroughs in biochemistry and cognitive science all aided in the evolution of neuroscience. As physicians continue to understand and diagnose neuronal diseases, scientists have diligently worked side-by-side to discover and develop innovative drugs as well as other alternative treatments.

Therefore, we at Gene Expression Systems, Inc., and Appasani Research Conferences decided to join together an array of speakers, including tenured professors, junior faculty members, postdoctoral fellows from academia, as well as entrepreneurs from venture backed neurodiscovery-based biotech companies and experienced executives from the pharmaceutical sector to maintain the motto of "Bridging Academia and Industry."

The Neuron to Synapse-2010 Meeting took place at the Holiday Inn Midtown in New York City, NY, USA, on June 7-8, 2010. An ideal location for the growing number of neuroscience laboratories; about 60 members of academia and industry gathered for 2 days of lectures on novel research techniques, new therapeutics, and drug development underway in the drastically growing field.

The keynote opening lecture was given by Dr. Robert Darnell of The Rockefeller University. Through the development of a novel technique, high-throughput sequencing of RNA isolated by crosslinking immunoprecipitation (HITS-CLIP), Dr. Darnell described how his lab is generating maps of RNA-protein interactions in living tissues to better understand how RNA regulation goes awry in human brain disease and cancer; specifically focusing on paraneoplastic neurologic disorders (PNDs). For his contributions to the field of neuroscience and upholding the true values of the role as a physician-scientist, the scientific committee presented Dr. Darnell with the "Physician-Scientist of the Year Award." This session on the "Neurobiology of Human Brain Diseases" continued with presentations from Dr. Ottavio Arancio of Columbia University who introduced the idea of amyloid-beta impairing memory in Alzheimer's disease. This presentation was followed up by Dr. Patrick May of Lilly Research Labs who presented new developments in secretase inhibitors for the treatment of Alzheimer's disease. Next, Dr. Paul Lombroso of Yale University presented his discovery of the molecule Striatal Enriched Protein Tyrosine Phosphatase (STEP) and his new novel treatments underway to improve cognition in Alzheimer's patients. Another talk was given by Dr. Shin-Ya Kawaguchi of the Kyoto University (Japan) in which he described a biophysical approach to studying the systems biology of plasticity at inhibitory synapses. The session ended with a final talk by Dr. Aiden Corvin of Trinity College Dublin in which he presented novel techniques to understanding the mechanism of schizophrenia etiology from genomic lessons.

The afternoon keynote session was given by Dr. Joseph LeDoux who was presented with the "Neuron Innovator Award" for his enormous research in determining the biological mechanisms of emotional memory. This session on "Learning \& Memory" continued with a talk by Dr. Yi Zhong of Cold Spring Harbor Laboratory in which he described memory development in Drosophila and his lab's novel approach to control "forgetting." Next, Dr. Robert Hawkins of Columbia University presented work on the role of spontaneous transmitter release in learning-related synaptic plasticity. The session ended with a talk by Dr. Lila Davachi of New York University who described work performed in her lab using fMRI technology to understand the mechanisms of memory formation and "forgetting".
The final session of the day ended with three talks by Dr. Songhai Shi of Memorial Sloan Kettering Cancer Centre, Dr. Stewart Anderson of Weill Cornell Medical College (New York City), and Dr. Ian Scott of Accucela, Inc. These speakers all presented their work on neuronal circuits and cortical migration in the mammalian neocortex.

The second day of the conference opened with a session on Neuro-developmental and psychiatric disorders. The first talk was given by Dr. Eric Nestler of the Mount Sinai School of Medicine in which he described novel techniques his lab is using to discover the epigenetic mechanisms of drug addiction. Next, Dr. Joan Fallon of Curemark, Inc., gave an industry keynote lecture on new drug developments and therapeutics that her company is developing for the treatment of autism and disorders in the autistic spectrum. Following this lecture, Dr. Wenzhen Duan of the Johns Hopkins University presented her labs work on potential therapeutic targets for Huntington's disease. Dr. Alistair Stewart next described phase 2 clinical trials being done at Allon Therapeutics, Inc., for the treatment of Alzheimer's disease and fronto-temporal dementia. This lecture was followed up by a presentation by Dr. Youming Lu of Louisiana University in which he described the role of NMDA receptor cell death signals at extra-synaptic sites. Dr. Christian Thomsen then described research being done at Lundbeck Research on the role of neuroprotective mechanisms in the treatment of Parkinson's disease. The session ended with a final presentation by Dr. David Bloom of the University of Florida on the use of viral vectors to restore hippocampal synaptic function in Fragile $\mathrm{X}$ Syndrome using a rodent model.

The final session of the day - and of the conference - ended with five talks on therapeutics for neurodegenerative diseases. Dr. Dani Brunner gave a wonderful overview of the various treatments and therapeutics underway at Psychogenics, Inc. 
Next, Dr. Amy Arnsten of Yale University described her novel technique on rescuing prefrontal cortical grey matter in various neuropsychiatric illnesses. Dr. Kenneth Rhodes next gave an overview of therapeutics currently underway at Biogen Idec. The final lecture of the conference was given by Dr. Wei-Qin Zhao of Merck Research Laboratories on $A \beta$ oligomerinduced synaptic loss via calcineurinmediated endocytosis.

Our primary goal for publicizing this conference was to exemplify the possibilities for cross-fertilization of scientific knowledge. The main focus of Gene Expression Systems, Inc., is to bring together members of industry and academia to one central location where collaborations can be made to give rise to the development of new therapeutics and drugs. By holding various meetings on the hot topics of the scientific world, we hope to continue to aid in the growth of translational medicine. We are grateful to the members of the scientific committee: Dr. Paul Lombroso of the Yale University School of Medicine, and Dr. Eric J. Nestler of the Mount Sinai School of Medicine. We would also like to offer our thanks to all of our sponsors as well as the Appasani Research Conferences Organization.

We also like to invite all members of the Frontiers community and members of the Neuroscience field to attend our upcoming European Neurodegenerative Diseases Meeting at the University of Oxford (UK) on September 20-21, 2010.

\section{BIOGRAPHY}

Raghu Kiran Appasani is a board member at Gene Expression Systems, Inc., as well as the Appasani Research Conferences \& Educational Institute. Currently, he is also an independent researcher in the field of developmental neurobiology and drug addiction. He received his training in the laboratories of Dr. Michael Greenberg of Harvard Medical School, Dr. Eric Kandel of Columbia University, Dr. Jingyue Ju of
Columbia University, Dr. Laurie JacksonGrusby of Harvard Medical School, Dr. Janice Naegele of Wesleyan University, and Dr. Eric Nestler of the Mount Sinai School of Medicine. As a board member of Gene Expression Systems, Inc., his major goal is to aid in the evolution of translational medicine in the treatment of neurological illnesses.

Conflict of Interest Statement: The author declares that the research was conducted in the absence of any commercial or financial relationships that could be construed as a potential conflict of interest.

Received: 19 June 2010; accepted: 02 July 2010; published online: 23 August 2010.

Citation: Appasani RK (2010) Aiding in the evolution of translational medicine: "Bridging Academia and Industry" in the field of neuroscience. Front. Neurosci. 4:56. doi: 10.3389/fnins.2010.00056

This article wassubmitted to Frontiers in Neurodegeneration, a specialty of Frontiers in Neuroscience.

Copyright (C) 2010 Appasani. This is an open-access article subject to an exclusive license agreement between the authors and the Frontiers Research Foundation, which permits unrestricted use, distribution, and reproduction in any medium, provided the original authors and source are credited. 